\title{
An Investigation of Authorial Visibility, Self-mention and Discourse Functions in Applied Linguistics Dissertations
}

\author{
Ebrahim Daryaee Motlagh \\ MA in TEFL (Teaching English as a Foreign Language) \\ Shahid Beheshti University \\ edaryaee@gmail.com
}

\begin{abstract}
This article follows Hyland's model of meta-discourse to probe into the question of author visibility, self-mention and discourse functions in Applied Linguistics dissertations. In this sense, the analysis of thirty theses and dissertations developed by postgraduate students was conducted at the University of Isfahan and the university's main library. The study focused mainly on sections developed and discussed by authors in these academic texts to study items such as discourse functions and the frequency of self-mention in submitted manuscripts. Among other things, the results of the study demonstrated that MA and PhD students of English and Applied Linguistics generally prefer an impersonal writing style in their dissertations as the frequency of third person narration was significantly higher than the use or frequency of first person (plural or singular) throughout the main sections of manuscripts. The study also showed that these authors adhere to the traditional rules of academic writing by adopting a formal style of writing.
\end{abstract}

Keywords: Applied linguistics; discourse analysis; self-mention; authorial visibility; discourse functions

\section{Introduction}

Academic writing has always been the subject of tremendous research especially in the fields of linguistics, pragmatics and discourse analysis. More specifically, the research in these areas is mainly focused on the manner in which academic texts are developed instead of focusing on the knowledge conveyed by these texts. Among the disciplines and branches of linguistics that study academic writing, discourse analysis is a relatively modern arena that approaches and analyzes language in terms of discursive qualities and contextual cues. The analysis of discourse structure and academic language is crucial as it fulfills a series of tasks, namely text summarization, information extraction and authorial presence. Generally, the discourse structure includes a wide range of practical elements such as the statement of claims, facts, arguments and hypotheses which are instrumental in understanding scientific articles. Due to this wide range of discourse functions, a great deal of research has been carried out in this area. For instance, Teufel et al. (2002) followed the principles of discourse analysis to analyze scientific papers in terms of the rhetorical status in rational propositions within an article and Coates (1996) used the same discipline to create a content model which was used to summarize information.

These studies have found that academic writing is characterized by a series of textbook principles and rules about writing and the aim of these principles seem to be the creation of an automatic framework to be followed by authors consistently. The prescriptive nature of these textbook principles is such that any deviation from these principles could lead to imprecision and lack of academic quality. Likewise, one of the areas of academic 
writing that is of particular interest to discourse analysts and language experts is the study of author visibility, author presence and self-mention in both general and academic texts. Writing is considered an active skill that establishes an interactive link between the writers and readers. For the same reason, analyzing the structure and organization of academic papers is given priority in discourse analysis. Furthermore, given the continuously growing number of scholarly papers and publications, there has been an increased interest in analyzing the textual aspects of author presence in academic writing (see, for instance, Dixon \& Foster, 1997; Hyland, 2005; Koeser \& Sczesny, 2014) and this area of linguistic research is the subject of the present study as well.

\section{Review of literature}

As mentioned above, academic writing is generally characterized by some norms and conventions, the most significant case of which is the formal writing style and the detachment of author in terms of selfmention in academic discussions. Following this line of reasoning, some scholars argue that spoken and written languages are often distinguished by paying attention to the signaling load, the message contents and interpersonal involvements (see, for instance, Tannen 1982; Petch-Tyson, 1998). In this sense, it has been posited by these scholars that, as a general rule, the spoken language is marked by the signaling load that focuses on interpersonal involvement while message content characterizes the written language. Written and academic discourse adheres to the rules of impersonality in the context of expository writing such as discussions and elaborations which rely on empirical and objective arguments following positivistic assumptions in the literature (Geertz, 1988). In some contexts, this particular feature is discussed as "authorevacuated" prose which is also supported by textbooks and guidelines available to the students of English or Applied Linguistics. The ultimate goal of the so-called author-evacuated prose is to prevent personal intervention and observe the standards of academic writing. Arguably, this objective and purely empirical perspective has been regarded significant in creating "clarity, economy, rational argument supported by evidence, caution and restraint" (Bennett, 2009, p. 52). In this connection, discourse analysts such as Hyland have described this as the absence of human agency in writing factual reports (see, Hyland, 2001). Accordingly, Hyland (1999) indicates that writing style manuals and courses offered at universities usually advise novice researchers to adopt a passive voice using impersonal constructions and highly abstract rhetoric. They are also asked to avoid the use of personal forms.

In fact, a review of literature shows that this prescriptive position is not without precedent. Following these proscriptions, the academic writing style is expected to have passive rather than active voice by omitting the agent of action (see, Hyland, 2002; Gong \& Dragga, 1995). For instance, Lester suggests that novice researchers should write their discussions using a third person voice avoiding sentences which begin with "It is my opinion" or "I believe" (Lester, 1993, p. 144). Likewise, Spencer and Arbon advise beginner writers to abide by traditional and formal writing and avoid the use of "I" or "we" in academic papers because the paper as a whole is regarded as the work of the author (Spencer \& Arbon, 1996, p. 26). In general terms, academic writing styles focus on remaining objective in developing arguments and expressing ideas as reference to personal opinions or the use of personal pronouns are usually limited (Arnaudent \& Barret, 1984). In other words, it has been asserted throughout the literature that, by adhering to these conventions, the beginner writers may ultimately learn to develop and use "peculiar ways of knowing, selecting, evaluating, reporting, concluding and arguing that define the discourse of the community" (Bartholomae, 1986, p. 4). While it has been suggested that the author should write with authority and use passive voice to remain objective in academic contexts (see, Johns, 1997), arguments in favor of author visibility has also received general or increasing attention (For instance, Mills \& Water, 1986; Day, 1994; Swales \& Feak, 1994).

After providing lengthy arguments in a book entitled 'How to Write and Publish a Scientific Paper', Day asks "all young scientists to renounce the false modesty of previous generations of scientists" (Day, 1994, p. 166) and use the agent of action in a sentence even when it is "I" or "we". On the other hand, in establishing 
the rules of academic writing for graduate students, Swales and Feak mention that these recommendations help inexperienced writers to maintain an objective and scholarly tone in written materials and this does not mean that the use of "I" or "we" would make a piece of writing less formal or inappropriate (Swales and Feak, 1994, p. 20). In fact, the review of literature also suggests that the avoidance or use of these pronouns does not affect the scientific attitude reflected in a text with regard to qualities such as restraint in manner, honesty, integrity and caution in handling the facts.

With this in mind, it can be understood that different writers may project different degrees of authoritativeness or visibility in their manuscripts and this research attempts to analyze what is technically called 'authorial presence' in postgraduate essays. Arguably, it has been implied that author visibility is used by authors simply to support general or specific statements that convey evaluations, attitudes and judgments (Dontcheva-Navrátilová, 2013). It can also be inferred from the above discussion that writers deliberately and consciously make linguistic and rhetorical choices in creating written arguments in their research studies. According to Hyland (2005), these choices have two general functions, namely stance and engagement. The first function is measured by writer's involvement in the arguments and this involvement can be either marked or disguised. In other words, the authors of scientific texts usually take action to show their stance or standpoint in written arguments. However, the second function that is known as engagement deals with the alignment between the author and the reader. In this sense, readers are also included or engaged in the scientific discourse as active participants who need to be guided by the author in their quest towards intended interpretations (Hyland, 2005). The writers of scientific articles may be assisted by these aspects of authorial presence which are reflected in discourse processing in order to offer cohesive clues and construct coherent arguments. Thus, writers use the above elements consistently to allow for what is technically called 'dialogic space' in which their views are negotiated. There are some empirical studies focusing on this particular aspect of academic writing. For instance, Petch-Tyson (1988) studied four groups of non-native English students and native students to illuminate the degree of author visibility. The researcher used computer software to analyze features such as first and second personal pronouns which signal this visibility. The results of the study conducted by Petch-Tyson indicated that academic papers created by university students with an advanced level of English resembled oral conversations. In this case, the subjects under study overused the abovementioned pronouns. Of course, the research on this particular topic has continued through the decades with emphasis on language learners and university students. A case in point is the research performed by Cobb (2000) on English academic texts written by French leaners in Quebec or the study conducted by DontchevaNavrátilová (2013) on articles written in the areas studied by Applied Linguistics experts in order to identify the frequency of author-reference pronouns with regard to authorial presence. It appears that the use and frequency of pronouns are common in all of these studies. Interestingly, Hyland (1999) has stated that the writers of academic essays in social sciences may follow three goals by using personal pronouns. These authors use such pronouns to highlight their research priorities, order their thoughts and arguments and ultimately pave the way for their conclusions and theoretical standpoints. Following the same line of research, Hyland studied a large number of academic articles from several fields of science and found that self-mention as a feature of academic writing enabled authors to organize "an authorial self firmly established in the norms of the discipline and reflecting appropriate degree of confidence and authority" (Hyland, 2001, p. 216). Likewise, Harwood (2005) and Tang and John (1999) investigated the self-promotional role of these pronouns (i.e. "I" and "we") in articles published in prestigious journals that focused on different branches of science. They found similar results indicating that these pronouns are used mainly to promote the author's viewpoint.

With respect to what was discussed above, the frequency of pronominal discourse functions has been the subject of extensive research. In another study, Munoz (2013) investigated the role of personal pronouns and their discourse functions in 60 research articles published by Applied Linguistics experts. The findings of the study suggested that these authors use "I" to build a relationship with their readers and show their 
commitment to the arguments organized in their papers as this pronoun is expected to strengthen meaning and credibility.

According to the literature, the use of pronouns and the emerging patterns found in previous research have reflected three aspects of author's identity (see, for more discussion, Ivanic, 1998). These aspects include the autobiographical self, the discoursal self and finally the authorial self that is the subject of the present study. Simply put, the autobiographical self reflects the writer's past experiences and knowledge whereas the discoursal self is identified by the writer's image or voice demonstrated in a text. On the other hand, the authorial self as the focus of this study is the degree to which authors become directly involved in academic texts by claiming responsibility for their contents. As mentioned earlier, author visibility is characterized by the level of authoritativeness that authors summon in organizing their written statements when they use a variety of linguistic and rhetorical resources to create this visibility (see, for more information, Hyland, 1999; Kuo, 1999; Martin, 2000; Hunston \& Thompson, 2000).

\section{Theoretical framework}

The current study was based on the model of meta-discourse explained by Hyland (2005). Hyland's model is comprised of a number of linguistic resources with two broad categories, namely interactional and interactive categories. The interactive spectrum encapsulates a series of unique meta-discourse signals such as evidential and code glosses and a number of textual markers (e.g. frame markers, transition markers, and endophoric markers). On the other hand, the interactional spectrum encompasses other markers and signals such as attitude markers, engagement markers, hedges and self-mention. In fact, the interactional aspect of Hyland's model deals with significant cases like reader pronouns, shared knowledge, questions and directives.

As indicated earlier, the use and frequency of self-mention with first person pronouns enable the authors to highlight their unique arguments and viewpoints. This subject has been studied extensively by Hyland (2002) who asserts that the readers of academic articles can arrive at logical conclusions or form interpretations based on the writers' arguments and their personalized texts. Therefore, the use of "first person" is a significant instrument allowing authors to project their so-called authorial self by emphasizing their contributions and claims. Some discourse analysts view this as a pivotal feature of successful writers in creating academic papers. According to Hyland (2002), the pragmatic qualities of academic writing style may revolve around self-mention in some cases as this organizing feature empowers the authors to develop academic texts and create a rhetorical self. Thus, in terms of theoretical framework, there are strong implications in the literature that authorial pronouns are key elements in promoting the writer's identity through authority and personal commitment. This being said, novice researchers and writers are often hesitant about using authorial determiners or pronouns and this may result in less clearly stated positions and arguments.

\section{Materials and method}

As indicated in previous sections, thirty postgraduate dissertations and theses were analyzed in the current research and Table 1 shows their range in terms of discipline and level.

Table1. The content range of academic papers investigated in the present study

\begin{tabular}{|l|l|l|l|l|}
\hline Level & English & Applied Linguistics & English Literature & Total \\
\hline PG Diploma & 4 & 0 & 0 & 4 \\
\hline MA & 4 & 5 & 3 & 12 \\
\hline PhD & 5 & 4 & 5 & 14 \\
\hline Total & 13 & 9 & 8 & 30 \\
\hline
\end{tabular}


The analysis of author visibility and self-mention was limited to the following sections of the theses and dissertations under study. In this sense, an attempt was made to review all the significant aspects of postgraduate dissertations by focusing on abstracts, declarations, statement of the problem, significance of the study, statement of aim and objectives, review of literature, theoretical frameworks, research methodologies, presentations, data analyses, conclusions, recommendations for further research and acknowledgement. For each section mentioned above, the use and frequency of self-mention was first noted with reference to the use of certain words and pronouns (i.e. "The Study" "The Author", "I", "We/Us/our", and "He/She"). Having recorded the frequency of occurrence for each case, the second stage was conducted by reviewing the use and frequency of self-mention discourse functions such as the statement of goals, results, arguments, elaborations, personal interactions, acknowledgements and self-beliefs. The review of the second stage also involved the same sections of the manuscripts mentioned above.

\section{Results and discussion}

The results of the study focus on the illumination of areas such as the use of signifiers related to author visibility, author presence and the presentation of self-mention discourse functions. Following this research priority, Table 2 summarizes the differences in the use and frequency of authorial visibility signals in the manuscripts under study.

Table 2. Author visibility signals in the manuscripts under study

\begin{tabular}{|c|c|c|c|c|c|c|c|}
\hline & We/us/our & I & $\begin{array}{l}\text { Third Person } \\
\text { / It }\end{array}$ & You & The author & The study & $\mathrm{He} / \mathrm{she}$ \\
\hline Abstract & 0 & 0 & 24 & 0 & 0 & 44 & 0 \\
\hline Declaration & 0 & 4 & 0 & 0 & 2 & 0 & 0 \\
\hline Objectives & 0 & 0 & 0 & 0 & 2 & 47 & 0 \\
\hline $\begin{array}{l}\text { Statement } \\
\text { of the problem }\end{array}$ & 5 & 1 & 0 & 0 & 1 & 11 & 0 \\
\hline Conclusions & 4 & 1 & 33 & 0 & 8 & 17 & 0 \\
\hline Significance & 0 & 0 & 1 & 0 & 2 & 43 & 0 \\
\hline $\begin{array}{l}\text { Theoretical } \\
\text { frameworks }\end{array}$ & 8 & 0 & 1 & 0 & 4 & 27 & 4 \\
\hline Literature review & 3 & 0 & 0 & 0 & 2 & 11 & 8 \\
\hline Methodologies & 0 & 0 & 4 & 0 & 3 & 48 & 3 \\
\hline Findings & 3 & 0 & 0 & 0 & 2 & 43 & 1 \\
\hline Acknowledgments & 0 & 7 & 26 & 0 & 2 & 44 & 0 \\
\hline Recommendations & 2 & 0 & 1 & 0 & 6 & 36 & 1 \\
\hline
\end{tabular}

A series of conclusions can be drawn based on the numerical data in Table 2. It can be seen that the impersonal writing style was more frequent in terms of the types of pronoun and this shows that the writers have made an effort to remain aloof and detached. The analysis of the above data brings us to the conclusion that the majority of postgraduate authors preferred invisibility as the frequency of third person narration was significantly higher than the use or frequency of first person (plural or singular) throughout the main sections of theses and dissertations. Table 2 also demonstrates that these authors adhere to the general rules of academic writing by adopting a formal and impersonal style even in acknowledgements and declarations which are generally considered as sections having an affective nature. Moreover, the results of the above table show a strong tendency for indicators such as "the study", "the author" and "Third person/It". These results 
are significant in that, in most cases, authors are expected to use personal or singular pronouns in sections dealing with acknowledgments and declarations in postgraduate theses. It should be noted that thesis writers highlight the authenticity, gratitude, originality and imperfections in these sections.

In dissertations, the statement of the problem is an important area in which authors are expected to be actively visible through self-mention and the use of personal pronouns in order to explain the research vacuum in the literature. However, there is only one instance for the use of singular pronoun by the authors. Moreover, the statement of study and objectives are among those sections that need active author visibility because the authors are expected to describe what they hope to achieve and what methodology they have decided to implement. Interestingly, there has been no First Person Pronoun (singular or plural) recorded for these sections. As indicated in Table 2, there is a general preference for the use of impersonal pronouns such as "third person / it", "the study" and "the author". On the other hand, the sections dealing with recommendations for further research also show a preference for the use of impersonal words such as "the study" (employed by 36 authors). Note that recommendations are generally expected to show the author's voice where authors become the explicit developer of the recommendations for further research. Therefore, as regards the use of authorial signifiers, the results in Table 2 suggest that the postgraduate writers who were the subjects of the present study show a significant tendency for detachment or what is sometimes called "linguistic aloofness" in their use of authorial signifiers.

The general use and frequency of authorial signifiers (i.e. nouns / personal pronouns) in terms of percentage was another aspect of the present study for all the sections of dissertations. Table 3 shows these percentages.

Table 3. The general percentage of authorial signifiers

\begin{tabular}{|l|l|l|l|l|l|l|c|}
\hline Authorial signifiers & He/she & You & We/us/our & The author & The study & I & Third Person / It \\
\hline Total percentage & $14 \%$ & $22 \%$ & $36 \%$ & $39 \%$ & $84 \%$ & $37 \%$ & $19 \%$ \\
\hline
\end{tabular}

The items shown in Table 3 are important in understanding author visibility as the percentage of "The study" is $84 \%$ which is higher than the rest of signifiers. Interestingly, these percentages show a high degree of detachment among the writers of postgraduate theses and dissertations. In the second rank, there is "the author" which is another form of author invisibility with a frequency of $39 \%$ in all the samples surveyed. Note that "the author" may refer to the writer of the text or another writer or researcher indicated in the texts. Regardless, this signifier shows some kind of non-committal and detached author reference. As observed in Table 3, there are also some cases of direct author involvement shown by the use of first person singular ("I") with a frequency of $37 \%$ which is the third rank and the first person plural (we/us/our) with a frequency of $36 \%$. Perhaps understandably, the authors used the second person (singular or plural) only in sections that pertain to affectivity (e.g. acknowledgements) because informal references are generally permissible in this section of theses and dissertations. Finally, third person pronominals ("It" and "He/She") are the least used signifiers with the frequency of $19 \%$ and $14 \%$ respectively.

On the other hand, the discourse functions indicated in this study were the statement of goals, results, personal interactions, the explanation of procedures, acknowledgements, arguments and the expression of selfbenefits. The discourse functions of self-mention can also be analyzed after the preliminary analysis of author visibility by presenting the frequency of pronouns and signifiers in different sample sections. Thus, the discourse functions of self-mention are shown in Table 4 based on the selected sections of postgraduate dissertations. 
Table 4. Self-mention discourse functions in writing samples

\begin{tabular}{|c|c|c|c|c|c|c|}
\hline & Goals & Results & $\begin{array}{l}\text { Interaction } \\
\text { Acknowledgement }\end{array}$ & Procedure & $\begin{array}{l}\text { Argument } \\
\text { elaboration }\end{array}$ & $\begin{array}{l}\text { Self-benefit } \\
\text { expressions }\end{array}$ \\
\hline Conclusions & 0 & 49 & 0 & 0 & 0 & 0 \\
\hline Declarations & 0 & 0 & 0 & 0 & 0 & 49 \\
\hline Abstract & 1 & 48 & 1 & 0 & 0 & 0 \\
\hline Acknowledgements & 0 & 0 & 48 & 0 & 0 & 1 \\
\hline Review of literature & 0 & 0 & 0 & 24 & 39 & 0 \\
\hline Findings & 0 & 51 & 0 & 0 & 0 & 0 \\
\hline $\begin{array}{l}\text { Research } \\
\text { methodologies }\end{array}$ & 1 & 0 & 1 & 44 & 0 & 5 \\
\hline Research objectives & 52 & 0 & 0 & 0 & 0 & 0 \\
\hline $\begin{array}{l}\text { Recommendations } \\
\text { for further research }\end{array}$ & 0 & 44 & 0 & 0 & 5 & 6 \\
\hline Problem statement & 42 & 0 & 0 & 0 & 10 & 0 \\
\hline Significance & 1 & 0 & 1 & 0 & 10 & 42 \\
\hline $\begin{array}{l}\text { Theoretical } \\
\text { frameworks }\end{array}$ & 0 & 0 & 0 & 9 & 44 & 0 \\
\hline
\end{tabular}

The above table demonstrates the discourse functions for each section chosen in postgraduate dissertations. According to table 4, the statement of results was mostly observed in the aspects of findings (51), conclusions (49), abstracts (48), and recommendations (44). Self-benefit expressions were largely observed in sections such as declarations (49) and the significance of the study (42). The statement of goals was a dominant feature in the sections dealing with objectives (52) and the statement of the problem (41).

The findings also demonstrate that interaction and acknowledgement are the dominant features in the acknowledgement section (48) while the explanation of research procedures are seen mostly in the review of literature (24) and research methodologies (44). The table shows that the review of literature consists of two discourse functions which are the explanation of research procedure (24) and argument elaboration (39). Moreover, aside from the discourse function of research procedure (44), self-benefit expressions are also observed in the section dealing with research methodology.

The section involving author's recommendations for further research shows three discourse functions which are the statement of results (44), argument elaborations (5) and expressing self-benefits (6) while the significance of the study consists of the statements of goals (1), self-benefits (42) and argument elaboration (10). The statement of the problem in the postgraduate dissertations consisted of two discourse functions which were the statement of goals with 42 occurrences and argument elaboration with 10 occurrences. Finally, the section discussing theoretical frameworks showed two self-mention discourse functions, namely argument elaboration (44) and the explanation of research procedure (9).

\section{Conclusion}

This paper followed Hyland's meta-discourse model to investigate the question of author visibility in theses and dissertations written by MA and PhD students of English and Applied Linguistics. As discussed earlier, the findings demonstrated that postgraduates and academic writers generally prefer author invisibility as the analysis of the main sections in available manuscripts pointed to the significant frequency of impersonal pronouns and signifiers. The findings also suggested that novice authors adhered to the general rules of academic writing by adopting a formal style of writing and avoiding the use of personal signifiers. In this 
manner, the postgraduates generally favored invisibility and tended to be very formal in their discussions and arguments. It can be concluded that adherence to academic traditionalism in which self-mention and the use of first person pronouns are regarded counterproductive is still the dominant norm among Iranian students of English and applied linguistics at advanced levels. Finally, it can be concluded that discourse functions observed in academic manuscripts vary significantly in terms of sections dedicated to the review of literature, acknowledgement, theoretical framework and the other areas of postgraduate dissertations. However, it should be noted as well that postgraduate research is often performed under some supervision and there are strict writing standards to be followed by $\mathrm{MA}$ and $\mathrm{PhD}$ students regardless of academic discipline. Therefore, these conclusions cannot be generalized to all disciplines and genres of academic writing and further research is required to shed light on the matter.

\section{References}

Arnaudet, M. \& M. Barrett (1984). Approaches to Academic Reading and Writing. Prentice Hall, Englewood Cliffs, NJ. Bartholomae, D. (1986). Inventing the University. Journal of Basic Writing, 5, 4-23.

Bennett, K. (2009). English Academic Style Manuals: A Survey. Journal of English for Academic Purposes, 8, $43-54$.

Coates, J. (1996). Women, men and language: A sociolinguistic account of gender differences in language. London: Longman.

Cobb, T. (2003). "Analyzing later Interlanguage with Learner Corpora: Quebec Replications of Three European Studies”. Canadian Modern Language Review, 59(3), 393-423.

Day, R. (1994). How to Write and Publish a Scientific Paper. Phoenix: Oryx Press.

Dixon, J. A., \& Foster, D. H. (1997). Gender and hedging: From sex differences to situated practice. Journal of Psycholinguistic Research, 26(1), 89-107.

Dontcheva-Navrátilová, O. (2013). "Authorial Presence in Academic Discourse: Functions of Author-reference Pronouns". Linguistica Progensia, 1, 9-30.

Geertz, C. (1988). Words and Lives: The Anthropologist as Author. Palo Alto, CA: Stanford University Press.

Gong, G. \& Dragga, S. (1995). A Writer's Repertoire. New York: Longman.

Harwood, N. (2005). Nowhere has Anyone Attempted... In this article I am to do just thate: A Corpus-based Study of Selfpromotional I and we in Academic Writing Across Four Disciplines". Journal of Pragmatics, 37, 1207- 1231.

Hunston, S. \& Thompson, G. (2000). Evaluation in Text. Oxford: Oxford University Press.

Hyland, K. (1999). "Disciplinary Discourses: Writer Stance in Research Articles". In: Candlin, C., Hyland, K. (eds.), Writing: Texts, Processes and Practices. pp. 99-121. London: Longman.

Hyland, K. (2001). Humble Servants of the Discipline? Self-mention in Research Articles. English for Specific Purposes, 20(3), pp. 207-226.

Hyland, K. (2002). Authority and Invisibility: Authorial Identity in Academic Writing. Journal of Pragmatics, 34, pp. $1091-1112$.

Hyland, K. (2005). Meta-discourse: Exploring Interaction in writing. London: Continuum.

Ivanič, R. (1998). Writing and Identity: The Discoursal Construction of Identity in Academic Writing. Amsterdam: John Benjamins.

Johns, A. (1997). Text, Role and Context. Cambridge: Cambridge University Press.

Koeser, S. \& Sczesny, S. (2014). Promoting gender-fair language: The impact of arguments on language use, attitudes, and cognitions. Journal of Language and Social Psychology, 33(5), 1-13.

Kuo, C. (1999). "The Use of Personal Pronouns: Role Relationships in Scientific Journal Articles". English for Specific Purposes, 18(2), pp. 121-138.

Lester, J. D. (1993). Writing Research Papers. New York: Harper Collins.

Martin, J. R. (2000). Analyzing Genre: Functional Parameters. In: Christie, F., and J.R. Martin (eds.), Genre and Institutions. London: Continuum.

Mills, G. \& Water, J. A. (1986). Technical Writing. Fort Worth, TX: Harcourt Brace Jovanovich.

Munoz, M.C. (2013). The "I" in Interaction: Authorial Presence in Academic Writing. Revista de Lingüísticay Lenguas Aplicadas, 8, 49-58. 
Petch-Tyson, S. (1998). Writer/Reader Visibility in EFL Written Discourse. In S. Granger (ed.). Learner English on Computer, pp. 107-118. London and New York: Longman.

Petch-Tyson, S. (1998). "Writer/Reader Visibility in EFL Written Discourse”. In S. Granger (ed.). Learner English on Computer, 107-118. New York: Longman.

Spencer, C. \& Arbon, B. (1996). Foundations of Writing: Developing Research and Academic Writing Skills. Lincolnwood, IL: National Textbook Co.

Swales, J. \& Feak, C. (1994). Academic Writing for Graduate Students: Essential Tasks and Skills. Ann Arbor, MI: University of Michigan Press

Tang, R. \& John, S. (1999). The "I" in Identity: Exploring Writer Identity in Student Academic Writing through the First Person Pronoun". English for Specific Purposes, 18, 23-39.

Teufel, S. \& Marc Moens, M. (2002). Summarizing scientific articles: experiments with relevance and rhetorical status. Computational Linguistics, 28(4), pp. 3-12. 